\title{
RELATIONSHIP BETWEEN EDUCATION AND POVERTY IN NEPAL
}

\author{
Surya Bahadur Thapa*
}

\begin{abstract}
Education is an important component of human resource development. It is the first most important determinant of income poverty. This paper aims to explore political economy of the country simply dealing with secondary data to produce the general statement relevant to the policy makers/ leaders of the country. In this context this paper tries to establish the linkage between income poverty and different levels of education. For this purpose secondary data published by United Nations Development Program and Central Bureau of Statistics were used. The descriptive findings based on these data provide fresh insights into some of the widely recognized perceptions on the extent and causes of educational deprivation of the poor that the level of educational attainment is a positive function of the levels of income.
\end{abstract}

Key Words: Education Poverty, Income Poverty, Literacy rate, Mean Years of Schooling, Gross Enrollment Rate

\section{INTRODUCTION}

Poverty has been defined as income poverty in conventional sense. Rowntree (1901) used this concept, at first, in his classic study of poverty of the English city of York. However, income poverty is widely used today being its own limitations. To overcome these limitations the United Nations Development Program (UNDP) has developed two alternative indices: Human Development Index (HDI) and Human Poverty Index (HPI). The UNDP has argued that poverty can evolve not only due to lack of the necessities of material well- being but also due to the denial of opportunities for living a tolerable life. The UNDP further elaborates that human poverty is more than income poverty: it is a rejection of choices and opportunities for living a tolerable life (UNDP, 1997). Education is one of the important determinants of human poverty the deprivation of which is called poverty of education. The poverty of education generates from poverty of income. Income poverty does not permit one to make adequate investment in education, and a low level of investment in education, finally, accentuates poverty. It is widely recognized that investment on education is one of the important keys to break the circular relationship of poverty of education (ADB, 2003). Sen $(1992,2001)$ argues that inadequate education could, in itself, be considered as a form of poverty. In the modern era, education is considered as a component of

${ }^{*} \mathrm{Mr}$ Thapa is Associate Professor of Economics of Education at the Central Department of Education, University Campus, TU. Phone: 016634457, Mobile: 9841637653. email: sooryathapa@yahoo.com; suryabahadur_thapa@yahoo.com 
basic need the lack of which contributes a lot to generate income poverty (Thapa, 2010). In totality it looks that these two concepts are interlinked but contain their own circular relationship. Investment in education, thus, in all countries is both privately and socially profitable (Thirlwall, 2006). Likewise it has frequently been reported that there is strong positive correlation between level of education and life time earnings (Todaro, 2001).

Education poverty that is related to income poverty exists at both micro and macro levels. At the micro level, illiterate individuals or households are less productive, join less- paying jobs, and remain at very low levels of living, mostly below poverty line. At the macro level, nations with illiterate or less educated masses can not progress well, not increase their output substantially, and as a result survive at low living standards. Moreover, the researches on poverty have found that education is the first most important determinant of income poverty. This has appeared true in case of Nepal. For example, The Nepal Living Standards Survey 2010/11 (NLSS III) has clearly shown that higher levels of educations are inversely correlated with income poverty and that lower income was associated with lower levels of family head's education. Similar findings are reported by Central Bureau of Statistics (CBS) (2011). It estimated the head count index is 33.48 percent among the illiterate population whereas it is only 7.11 percent among eleven class completed population (CBS, op. cit.). The significance of education on reducing poverty is that it generates variety of benefits. These benefits of education are classified as direct and indirect benefits. Education provides direct benefits in the form of higher income, more stable employment and better working condition (Psacharopoulos and Maureen, 1985) and in the form of indirect benefits such as people's empowerment with knowledge, improvement of values and institutions for better quality of life (ADB, 2003).

There is lack research on the linkage between education and poverty in Nepal. However, different empirical researches have established the linkage between education and poverty. For example, Faux and Ntembe (2013) investigated the impact of educational attainment on poverty in Cameroon. The study employed a logistic regression model to investigate the probability of an individual being poor using gender, work experience and levels of education as explanatory variables. The estimated coefficients show that that as one's level of education increases, the probability of being poor decreases. Afzal et al. (2012) examined the relationship between education, poverty and economic growth in Pakistan based on secondary data for the time period of 1971/72 - 2009/10. They found that Education affects real GDP positively and significantly only in the long run and conclude that better education can be an effective tool for poverty reduction and enhancing economic growth. Awan et al. (2011) evaluated the effect of education on poverty in Pakistan based on the secondary data for the years 1998/99 2001/02. They concluded that education and poverty are inversely related. The higher the level of education of the population lesser will be the number of poor persons. 
Berg (2008) analyzed the relationship between education and poverty in developed and developing countries. He explained that access to education differs depending on income levels and presented the clear evidence that education can reduce poverty in number of ways. However, poverty is just one of several factors that prevent access to education. Knight et al. (2007) analyzed relationships between education and income in rural China based on the data from a national household survey for 2002. They found the evidence that community enrolment is positively related to community income and suggest that providing education and increase in income reduce the risk of being in poverty.

The main aim of this paper is to explore political economy of the country simply dealing with secondary data to produce the general statement relevant to the policy makers/ leaders of the country. Once the general statements that indicate the relationship between education and poverty are produced, it is probable that it may attract the attention of political leaders and policy makers alike to understand the importance of education in order to alleviate the poverty in the country. In this context this paper tries to establish the linkage between poverty (in terms of consumption quintile) and different dimensions of education (literacy rate, type of schools attended by individuals' currently in school, gross enrollment rate, mean years of schooling and reasons for not attending schools and dropouts).

The paper is organized as explained below. Section two outlines the research methodology and the sources of data. Section three presents bird's eye view on education and income poverty in South Asia. Section four discusses incidence of income poverty and different dimensions of educational in Nepal. The last section provides conclusion.

\section{RESEARCH METHODOLOGY AND THE SOURCES OF DATA}

This paper follows descriptive research method based on the secondary data collected and published by Central Bureau of Statistics (CBS). The CBS conducted Nepal Living Standards Survey covering three different times (in 1995/96, 2003/04, and 2010/11) following the Living Standards Measurement Survey (LSMS) methodology developed and promoted by the World Bank. These surveys have incorporated wide range of data including socio economic characters of the population. The importance of the nation wide collected data is that it provides different dimensions of education including literacy rate, type of schools attended by individuals' currently in school, gross enrollment rate, mean years of schooling and reasons for not attending schools and dropouts among others connecting these with consumption quintile. The consumption quintiles were presented into five groups: from poorest to richest. Finally, the various dimensions education were presented with these categories of consumption quintile. 


\section{EDUCATION AND POVERTY IN SOUTH ASIA}

South Asia is the poorest region of the world where more than 570 million population lives below the poverty line which accounts for the largest proportion $(44 \%)$ of the worlds' poor population that survive on less than \$1.25 -a - day. Nearly 98 percent of the world's illiterate population lives in developing countries. Half of these people live in South Asia (Siddiqui, 2006). The adult illiteracy rate in this region is more than 40 percent (UNDP, 2013). A brief account of South Asia region's income poverty and education profile is presented in Table 1.

Table 1: Income Poverty and Education Profile of South Asia

\begin{tabular}{|c|c|c|c|c|c|c|c|c|}
\hline \multirow[t]{2}{*}{ Countries } & \multirow{2}{*}{$\begin{array}{c}\text { Income } \\
\text { Poverty } \\
(2002- \\
11)\end{array}$} & \multicolumn{3}{|c|}{ Education Poverty } & \multicolumn{3}{|c|}{$\begin{array}{l}\text { Gross Enrollment Ratio } \\
\text { (\%) }(2002-11)\end{array}$} & \multirow{2}{*}{$\begin{array}{l}\text { Percent of } \\
\text { GDP spent on } \\
\text { education }\end{array}$} \\
\hline & & 1 & 2 & 3 & 4 & 5 & 6 & \\
\hline Bangladesh & 43.3 & 56.8 & 33.8 & 4.8 & n.a. & n.a. & 10.6 & 2.2 \\
\hline Bhutan & 10.2 & 52.8 & 9.0 & 2.3 & 111 & 70 & 8.8 & 4.0 \\
\hline India & 32.7 & 62.8 & 34.2 & 4.4 & 118 & 60 & 16.2 & 3.1 \\
\hline Maldives & n.a. & 98.4 & 2.3 & 5.8 & 109 & 71 & n.a & 8.7 \\
\hline Nepal & 24.8 & 60.3 & 38.3 & 3.2 & 115 & 44 & 5.6 & 4.7 \\
\hline Pakistan & 21.0 & 54.9 & 38.5 & 4.9 & 95 & 34 & 5.4 & 2.4 \\
\hline Sri Lanka & 7.0 & 91.2 & 1.4 & 9.3 & 99 & 87 & 15.5 & 2.1 \\
\hline South Asia & n.a. & 62.8 & 21.4 & n.a. & 113.6 & 57.6 & 15.7 & n.a. \\
\hline
\end{tabular}

Source: Human Development Report 2013 for all indicators except fifth and last column which is adopted from Human Development Report 2012.

Note: n.a.= not available; 1 = Adult literacy rate (2005-10): It is a percentage of the population ages 15 and above who can, with understanding, both read and write a short simple understanding on their everyday life. 2 = primary school dropout rate as percent of primary school cohort (2002-11). It is calculated as 100 minus the survival rate to the last grade of primary education and assumes that observed flow rates remain unchanged throughout thee cohort life and that dropouts do not re-enter school. 3 = Mean years of schooling. Gross enrollment ratio is the total enrollment in a given level of education within a country regardless of age expressed as a percentage of the population in the official age group corresponding to this level of education ( $4=$ Primary, 5= secondary, 6 tertiary). Income poverty is the percentage of the population below \$ 1.25 PPP per day)

Table 1 shows income poverty and education profile of South Asia. It contains income poverty, education poverty, gross enrollment ratio and public expenditure as percent of Gross Domestic Product (GDP) of seven countries. Table 1 clearly indicates that 
there is negative relationship between income poverty and adult literacy: as income poverty decrease adult literacy rate increase. For example, in Sri Lanka income poverty is 7 percent and adult literacy rate is 91 percent. In Bangladesh, income poverty is 43 percent and adult literacy rate is 57 percent. The table also shows that there is positive relation between income poverty and primary school dropout rate. As income poverty declines primary school dropout rate also declines. For example, the primary school dropout rate of Sri Lanka is 1.4 while that of Bangladesh is 33.8. Similarly, Table 1 exhibits negative relationship between income poverty and mean years of schooling. As is illustrated, the mean years of schooling of Sri Lanka is 9.3 and that of Bangladesh is only 4.8. Table 1 also reveals relationship between gross enrollment ratio (GER) and income poverty. In relation to tertiary level, the GER increases with the decline in income poverty. It confers that to go to schools people have to fulfill their economic needs. In totality, Table 1 has concluded that in South Asian countries there is negative relationship between income poverty and educational attainment. However, it has also been argued that education is not only the income determined concept but also influenced by social phenomenon (Thapa, 2011).

\section{INCIDENCE OF INCOME POVERTY AND EDUCATION IN NEPAL}

Education in Nepal was not available to the common people, before 1951. It was restricted only to the members of the ruling families. But after the revolution of 1951, education policies have frequently been changing in favor of the general public. Several efforts were made during the Panchayati system to expand education both in quality and quantity. After the restoration of multiparty system in the country in 1991, the pace of educational development took full momentum. So far, various educational policies and projects were implemented in Nepal. Recently, the government of Nepal is planning to provide universal primary education by the year 2015 viewing crucial important to reduce poverty. But the low level of income in the country has remained a major hindering factor to make primary education universal in Nepal.

As stated above there is close link between education and income poverty. Income poverty varies inversely with the level of educational attainment. However, there was a dearth of data to verify this phenomenon in Nepal. Later, CBS conducted three consecutive surveys on education and income amid others of Nepalese people. The results of the survey were published in the form of Nepal Living Standards Survey 1995/96 (NLSS I), Nepal Living Standards Survey 2003/03 (NLSS II), and Nepal Living Standards Survey 2010/11 (NLSS III). The data published in the reports are used herein to establish the link between income poverty and educational poverty. This is done in Table 2. Table 2 shows linkage between income poverty and different dimensions of education. 
Table 2: Income Poverty and Educational Poverty in 1995/96, 2003/04, 2010/11

\begin{tabular}{llll}
\hline \multicolumn{1}{c}{ Description } & NLSS I & NLSS II & NLSS III $^{\Psi}$ \\
\hline Income poverty $^{*}$ & 41.76 & 30.85 & 25.16 \\
Adult Illiteracy $^{*}$ & 64.4 & 52 & 43.5 \\
Mean years of schooling & 7.0 & 7.5 & 8.1 \\
Schools ever attended \% & 33.9 & 45.8 & 54.6 \\
Gross enrollment rate (secondary ) & 11 & 54 & 73.6 \\
Net enrollment rate (secondary) & 9 & 15 & 15 \\
Public schools attended by individuals (\%) & 89.67 & 81.6 & 71.9 \\
Private schools attended by individuals (\%) & 8.5 & 16.7 & 26.8 \\
\hline
\end{tabular}

Note: 100 minus adult literacy rate gives adult illiteracy rate.

Source: * CBS (1996); $\gamma$ CBS (2004); $\Psi$ CBS (2011)

Table 2 presents incidence of income poverty and education poverty in Nepal based on NLSS I, NLSS II and NLSS III. According to Table 2, the income poverty as measured by head count index is declining over the years. During the period of 8 years, from NLSS I to NLSS II, the income poverty rate declined from 41.76 to 30.85 percent. Similarly in 7 years, from 2003/04 to 2010/11, it further declined from 30.85 to 25.16 percent. Thus, the income poverty in Nepal has declined nearly by 11 percentage points (or 26 percent) and almost 6 percentage points (or almost 18 percentage) during the periods of NLSS I (8 years) and NLSS II (7 years) respectively. The exponential growth rate suggest that the poverty declined by 3.78 percent annually in between NLSS I and NLSS II and by 2.68 percent during NLSS II and NLSS III. The poverty rate has declined faster during the period of NLSS I and NLSS II as compared to NLSS II and NLSS III.

Table 2 also shows adult illiteracy rate. This adult illiteracy has declined continuously in 15 years from NLSS I to NLSS III. The adult literacy rate has declined by 12.4 percentage points (or 19.25 percent) and declined by 2.67 percent annually during the period of NLSS I and NLSS II. The rate has declined by 8.5 percent points (or 16.34 percent) and reduced by 2.54 percent annually during in between NLSS II and NLSS III. The adult illiteracy rate has declined faster during the period of NLSS I and NLSS II as compared to NLSS II and NLSS III.

Table 2 shows that the mean years of schooling has increased throughout the survey years. In between NLSS I and NLSS II, the mean years of schooling increased by 0.5 percentage points (or by 7.14 percent). The mean years of schooling has increased by 0.86 percent annually during the period of 8 years. Similarly, in between NLSS II and NLSS III, it has increased by 0.6 percentage points (or 8 percent). The mean years of schooling increased by1.09 percent annually during the same period. It has increased faster during the period of NLSS II and NLSS III as compared to NLSS I and NLSS II. 
As presented in Table 2 the school attended rate has increased throughout the years. In between NLSS I and NLSS II, the rate has increased by 11.9 percent points (or by 35.1 percent). The school ever attended rate increased by 3.76 percent annually during the period of 8 years. Similarly, in between NLSS II and NLSS III, it increased by 8.8 percentage points (or 19.21 percent). It has increased by 2.51 percent annually during the same period. The school attended rate has increased faster during the period of NLSS II and NLSS III as compared to NLSS I and NLSS II.

As founded in Table 2 both the gross enrollment rate and net enrollment rate have increased with the decline in income poverty. As poverty declines the percentage of population attending public school is declining and that of private school attending is increasing. It confers that as income permits people prefer private to public schools. One possible reason for this bitter fact is that there is always complain about the quality of education in public schools.

\subsection{Literacy Rate and Income Poverty}

Literacy is universally linked with poverty reduction. The higher extent of illiteracy in the world corresponds to high levels of poverty - a complex cycle of deprivation, implying a high level of vulnerability (UNESCO, 2013). In Nepal the above fact seems exactly true. The literacy rate appears lower among the poor and higher among the richer. Nepal's literacy rate by consumption quintile is presented in Table 3.

Table 3: Literacy Rate by Consumption Quintile: Population 15 Years and Older

\begin{tabular}{lrrr}
\hline Consumption quintile & NLSS I $^{*}$ & NLSS II $^{\gamma}$ & NLSS III $^{\Psi}$ \\
\hline Poorest & 19.04 & 23.1 & 36.8 \\
Second & 25.92 & 34.9 & 44.8 \\
Third & 28.86 & 43.3 & 52.2 \\
Fourth & 42.15 & 55.1 & 61.6 \\
Fifth & 55.47 & 72.3 & 77.4 \\
Nepal & 35.57 & 48.0 & 56.5 \\
\hline
\end{tabular}

Source: *CBS (1996); $\gamma$ CBS (2004); $\Psi$ CBS (2011)

Table 3 presents literacy rate by consumption quintile. The table clearly indicates that literacy rate has increased with the consumption quintile. It is evident from the table that the literacy rate of the poorer is lower compared to that of richer. For example, the literacy rate of the poorest quintile is 19.04, 23.1, and 36.8 in NLSS I, NLSS II, NLSS III respectively. The figure for the fifth quintile is 55.47, 72.3 , and 77.4 in NLSS I, NLSS II, NLSS III respectively. So the table concludes that there is negative relationship between literacy rate and house hold's income (poverty). Consequently as literacy rate increases income poverty decreases. 


\subsection{Type of Schools attended by Individuals and Income Poverty}

Type of schools attended by individuals' is one dimension of educational quality. It is highly vowed perception that poorer go to community or government schools and richer attend private schools. Let's test this bitter fact on the basis of data collected from NLSS I, NLSS II and NLSS III. It is presented in Table 4.

Table 4: Types of School Attended by Individuals Currently in School, in Percentage, According to Consumption Quintile

\begin{tabular}{ccccccc}
\hline \multirow{2}{*}{$\begin{array}{c}\text { Consumption } \\
\text { quintile }\end{array}$} & \multicolumn{2}{c}{ NLSS I $^{*}$} & \multicolumn{2}{c}{ NLSS II $^{\gamma}$} & \multicolumn{2}{c}{ NLSS III $^{\Psi}$} \\
\cline { 2 - 7 } Poorest & 1 & 2 & 1 & 2 & 1 & 2 \\
\cline { 2 - 7 } Second & 94.26 & 4.0 & 90.1 & 5.3 & 92.7 & 6.4 \\
Third & 95.17 & 1.27 & 94.5 & 3.5 & 86.5 & 11.2 \\
Fourth & 93.11 & 2.88 & 92.6 & 6.5 & 79.1 & 19.8 \\
Fifth & 81.39 & 5.72 & 84.2 & 14.5 & 64.3 & 34.7 \\
Nepal & 89.67 & 7.45 & 81.6 & 16.9 & 39.0 & 60.1 \\
\hline
\end{tabular}

Source: * CBS (1996); $\gamma$ CBS (2004); $\Psi$ CBS (2011).

Note: 1 = government schools. $2=$ private schools.

Table 4 shows the types of school attended by individuals currently in school based on three Nepal Living Standards Surveys. Table says that most of the (92.7\%) students from the poorest group go to the community schools and only 6.4 percent from this quintile go to the private schools according to the data from NLSS III. It further says that the richest quintile, 60 percent students go to the private schools and 39 percent go to the government schools as reported by the same survey. The same trend is also true in NLSS I and NLSS II.

The table shows the positive relationship between private school goers and income levels: the increase in private school goers increases confers increase in the levels of income. Likewise there is negative relationship between government school goers and income levels: the decrease in the government school goers is due to the increase in income levels. Finally, it can be deduced from the table that private schools are the schools of the richer whereas government schools are for poorer.

\subsection{Gross Enrollment Rate and Income Poverty}

Gross enrollment rate (GER) is the ratio of the total number of students enrolled in school at a given level of education irrespective of their age to the total number of children in the age group specified for that level of education. The relation between GER and income poverty is presented in Table 5 . 
Table 5: Gross Enrollment Rate (GER) at Secondary Level by Consumption Quintile

\begin{tabular}{lrcc}
\hline Consumption quintile & NLSS I & \multicolumn{1}{c}{ NLSS II $^{*}$} & NLSS III $^{\Psi}$ \\
\hline Poorest & n. a & 10 & 41.4 \\
Second & n.a. & 27 & 58.9 \\
Third & n. a. & 46 & 74.0 \\
Fourth & n. a. & 74 & 83.8 \\
Fifth & n. a. & 102 & 109.1 \\
Nepal & 11 & 54 & 73.6 \\
Poverty rate & 41.76 & 30.85 & 25.16 \\
\hline
\end{tabular}

Source: * CBS (1996); $\gamma$ CBS (2004); $\Psi$ CBS (2011)

Table 5 presents comparative figures of income poverty and gross enrollment rate by consumption quintiles based on NLSS II and NLSS III. It gives the evidence that as consumption quintile goes from poorest to richest the enrollment rate has increased in all Living Standard Surveys. For example, based on the NLSS II and NLSS III, the gross enrollment rate of the poorest quintile is 10 and 41.4 respectively. Similarly, the rate of the richest quintile is 54.0 and 73.6 respectively. A bird's eye view on the table reveals that there is an inverse relationship between gross enrollment rate and income poverty: as gross enrollment rate increases at national level as well as consumption quintile the income poverty declines.

\subsection{Mean Years of Schooling and Income Poverty}

The mean years of schooling are the years of formal schooling, of an average, of an individual who ever attended school. The mean year of schooling is a popular measure of human capital investment. The mean years of schooling in relation to consumption quintile is shown in Table 6.

Table 6: Mean Years of Schooling, Who Ever Attended School (of 15 Years and Above)

\begin{tabular}{lrrc} 
Consumption quintile & NLSS I $^{*}$ & NLSS II $\gamma$ & NLSS III $\Psi$ \\
Poorest & 5.20 & 5.1 & 6.0 \\
Second & 5.94 & 6.0 & 6.7 \\
Third & 6.28 & 6.8 & 7.3 \\
Fourth & 6.87 & 7.3 & 8.1 \\
Fifth & 8.35 & 9.2 & 9.9 \\
Nepal & 7.00 & 7.5 & 8.1 \\
\hline
\end{tabular}

Source: * CBS (1996); $\gamma$ CBS (2004); $\Psi$ CBS (2011)

Table 6 presents mean years of schooling of all adult population (age 15 and plus) for those who ever attended school. A cursory look on the table indicates that there is positive relationship between economic levels as shown by the consumption quintiles, and mean years of schooling. The level of education as reflected by mean years of schooling increases as the level of households' expenditure/ income increases. For the 
poorest quintile, mean years of schooling for, total population, is 6.0 which is 9.9 for the richest quintile according to NLSS III. Thus it gives the general statement that mean years of schooling is positively associated with consumption quintile: as consumption quintile goes from poorest to richest mean years of schooling increases.

\subsection{Reasons for Not-Attending School and Drop Out}

Why do children not go to school and why do they dropout after enrolling the school? Generally it is considered that poverty in Nepal prevents families from sending their children to school and it acts as a catalyst for drop out. It has already been noted that both non enrollment and drop out rates are higher among the poorest sections of the population than among the richer sections. It would be useful to search the answers to the respondents about why do not children go to school and if they go why do they drop out earlier? The NLSS I, NLSS II, and NLSS III have identified different reasons. Let us concentrate on these two aspects.

\subsubsection{Reasons for Not- attending School}

Why do children not go to school? It is a major hurdle in the expansion of education. Thus, it is quite useful to search the answers on why did not children like to go to school? For this, the NLSS I and NLSS II had recorded 7 reasons while the NLSS III has identified eight reasons. The major reasons in terms of extent of not attending school are presented in Table 7. These are only major reasons and the minors are not shown, so that their sum is not 100 percent.

Table 7: Reasons for Not Attending School for All Population 6-24 Years Who Have Never Attended School in the Past (in Percent)

\begin{tabular}{|c|c|c|c|c|c|c|c|}
\hline & \multicolumn{6}{|c|}{ Consumption Quintile } & \multirow[t]{2}{*}{ Nepal } \\
\hline & Causes & First & Second & Third & Fourth & Fifth & \\
\hline \multirow{5}{*}{ NLSS I* } & 1 & 22.98 & 21.06 & 17.48 & 18.31 & 11.58 & 19.83 \\
\hline & 2 & 4.94 & 2.47 & 3.62 & 4.27 & 4.32 & 3.89 \\
\hline & 3 & 19.31 & 18.53 & 19.13 & 21.87 & 36.45 & 20.67 \\
\hline & 4 & 26.64 & 33.93 & 30.10 & 32.62 & 23.57 & 29.86 \\
\hline & 5 & 12.60 & 9.46 & 10.87 & 8.85 & 8.73 & 10.62 \\
\hline \multirow{5}{*}{ NLSS II ${ }^{\gamma}$} & 1 & 22.4 & 18.9 & 15.4 & 14.5 & 19.1 & 19.3 \\
\hline & 2 & 3.8 & 2.6 & 1.8 & 1.3 & 0.9 & 2.7 \\
\hline & 3 & 15.3 & 23.8 & 25.2 & 22.8 & 19.4 & 20.3 \\
\hline & 4 & 29.1 & 34.1 & 38.2 & 32.6 & 38.0 & 32.8 \\
\hline & 5 & 15.7 & 9.4 & 10.3 & 17.1 & 8.4 & 12.9 \\
\hline \multirow{5}{*}{ NLSS III $^{\Psi}$} & 1 & 8.6 & 9.0 & 4.8 & 3.7 & 7.1 & 7.5 \\
\hline & 2 & 4.5 & 1.0 & 4.1 & 0.0 & 0.0 & 2.8 \\
\hline & 3 & 28.0 & 35.2 & 24.5 & 27.6 & 34.6 & 29.6 \\
\hline & 4 & 34.5 & 35.0 & 37.2 & 35.1 & 36.8 & 35.3 \\
\hline & 5 & 11.7 & 12.1 & 15.6 & 15.8 & 5.8 & 12.7 \\
\hline
\end{tabular}

Source: * CBS (1996); $\gamma$ CBS (2004); $\Psi$ CBS (2011)

Note: $1=$ too expensive, $2=$ too far, $3=$ help to family, $4=$ parent did not want, $5=$ not willing to attend 
Table 7 presents major reasons for not attending school based on three Nepal Living Standards Surveys. There are various reasons for not attending schools. The most dominating reason (ranges from $34-37 \%$ ) for not attending school/non enrollment of the children of the age group 6- 24 years in total population is found to be "parents did not want to send their children in the school" which is followed by "help to family" (ranges from 28 to 35\%) and "not willing to attend" (ranges from 5 - 15\%) in NLSS III. The same is true for NLSS II and NLSS I also. These reasons are more or less true for all income groups. As poverty declines the extent of the reason "too far and too expensive" has declined. According to the consumption quintile, the school is "too expensive and too far" for the poorest section. These all altogether suggest that there is inverse relationship between levels of income and percentage of respondents responding as "too expensive" and "too far" school.

\subsubsection{Reasons for Dropout}

Why do children dropout after enrolling the school? This is another challenge to the education experts and education policy makers. The NLSS II, and NLSS III have identified various reasons for drop out. Even though, such reasons were not recorded in NLSS I and thus not included in the table. The major reasons with their extent are presented in Table 8.

Table 8: Major Reasons for Dropout for Population 6-24 Years Who Attended School in The Past

\begin{tabular}{|c|c|c|c|c|c|c|c|}
\hline & \multicolumn{6}{|c|}{ Consumption quintile } & \multirow[t]{2}{*}{ Nepal } \\
\hline & Causes & First & second & Third & Fourth & Fifth & \\
\hline \multirow{5}{*}{ NLSS II $\gamma$} & 1 & 19.4 & 10.1 & 11.0 & 10.3 & 8.9 & 11.5 \\
\hline & 2 & 29.3 & 31.2 & 31.4 & 32.1 & 33.3 & 31.6 \\
\hline & 3 & 27.1 & 29.0 & 29.2 & 25.9 & 22.7 & 26.8 \\
\hline & 4 & 7.5 & 12.3 & 7.2 & 8.0 & 7.0 & 8.5 \\
\hline & 5 & 2.6 & 2.1 & 5.4 & 3.9 & 4.6 & 3.8 \\
\hline \multirow{5}{*}{ NLSS III ${ }^{\Psi}$} & 1 & 11.3 & 6.8 & 5.7 & 5.0 & 3.9 & 6.5 \\
\hline & 2 & 18.2 & 28.0 & 25.6 & 24.5 & 25.8 & 24.6 \\
\hline & 3 & 27.6 & 27.6 & 21.5 & 16.6 & 17.1 & 22.0 \\
\hline & 4 & 10.0 & 6.8 & 8.9 & 5.2 & 6.2 & 7.4 \\
\hline & 5 & 2.1 & 1.3 & 1.1 & 2.3 & 2.5 & 1.8 \\
\hline
\end{tabular}

Source: * CBS (1996); $\gamma$ CBS (2004); $\Psi$ CBS (2011)

$1=$ too expensive, $2=$ poor academic progress, $3=$ help to family, $4=$ parent did not want, $5=$ completed desired level, n.a.= not available.

Table 8 presents reasons for drop out. A cursory look on the table shows that the main reason (ranges from $18-28 \%$ ) for the drop out of the children of the age group 6- 24 
years is found to be "poor academic progress" which is followed by "help to family" (ranges from 16.6 to $27.6 \%$ ) and "parents did not want" (varies from $5.2-10.0 \%$ ) based on the data of NLSS III. This is also more or less true in NLSS II. The school is "too expensive" and "parents did not want" are the main reasons for those who are from poor families. Thus it is found that there is inverse relationship between levels of income and percentage of respondents responding as "too expensive" and "parents did not want".

It would be useful to make further enquiry into the theses causes ("parents did not want", "help at home" and "not willing to attend school") as probable answers could be others such as absence of knowledge of the potential benefits of education to the parents, or need of children as a care taker in home, and also not appropriate school environment etc. However, this information was not collected by survey which may be necessary to extend the text further. Let us hope that this will be included in the future survey. Thus the present analysis ends here.

\section{CONCLUSION AND RECOMMENDATIONS}

Education is the first step in the way of development process and it provides the basis for the improvement of the socio-economic condition of a country. It is life empowering instrument for all which the poor need most. It empowers poor by attacking ignorance, creating positive attitudes and making them more productive. The ultimate result is increase in productivity and hence earning capacity of the poor. Despite such crucial importance of education, it has still been neglected in South Asia as there is very lower percentage of GDP is allocated for this sector. This could be the result of the elite dominated political superstructure in the country. This paper presented briefly the linkage between income poverty and education in Nepal. The conclusions of the study are as follows: (i) that there is negative relationship between literacy rate and household's income (poverty): as literacy rate increases income poverty decreases, (ii) that there is positive relationship between private school goers and income levels: as income level increases the percent of private school goers increases. Likewise there is negative relationship between government school goers and income levels: as income level increases the percent of government school goers decreases, (iii) that there is an inverse relationship between gross enrollment rate and income poverty: as poverty declines the gross enrollment rate increases at national level and consumption quintile as well, (iv) that mean years of schooling is positively associated with consumption quintile: the mean years of schooling has increased with the increase in consumption quintile.

The present analysis clearly concludes that the educational attainment is a positive function of the level of income and negative function of educational attainment Though many of the findings presented herein are not new in the textual context, the empirical evidence discussed here provides fresh insights into the perceptions on the extent and causes of educational deprivation of the poor in the context of Nepal. This conclusion 
is similar to that of Faux and Ntembe (2013), Afzal et al. (2012), Awan et al. (2011), Berg (2008) and Knight et al. (2007).

Based on the above conclusions, thus, it is recommended that the Government of Nepal is bound to increase the volume of investment (overall in general and educational in particular) in terms of both fiscal and national efforts if the government is truly willing to reduce poverty of the poorer in Nepal.

\section{References}

ADB (Asian Development Bank) (2003). Education. Manila: ADB.

Afzal, M., Malik, M. E., Begam, I., Sarwar, K. \& Fatima, H. (2012). Relationship among education, poverty and economic growth in Pakistan: an econometric analysis. Journal of Elementary Education, 22(1), 23-45

Awan, M. S., Malik, N., Sarwar, H., \& Waqas, M. (2011). Impact of education on poverty reduction. Munich Personal RePEc Archieve (MPRA)

Berg, S. V. D. (2008). Poverty and education. Brussels, Belgium: International Academy of Education (IAE) and International Institute for Educational Planning (IIEP).

CBS (Central Bureau of Statistics) (2011). Nepal living standards survey 2010/11. Vol. I. Kathmandu: Author

CBS (Central Bureau of Statistics) (2004). Nepal living standards survey 2003/04. Vol. I. Kathmandu: Author

CBS (Central Bureau of Statistics) (1996). Nepal living standards survey 1995/96. Vol. I. Kathmandu: Author

Faux, E \&. Ntembe, A. (2013). Does education reduce poverty? Response from Cameroon. World Journal of Social Sciences 3,(2), $114-126$.

Knight, J., Shi, L. \& Quheng, D. (2007). Education and the poverty trap in rural China. DFID and University of Cambridge. RECOUP Working Paper 11.

Psacharopoulos, G., \& Maureen, W. (1985). Education and development: An analysis of investment choices. Washington D. C.: The World Bank.

Rowntree, S. (1901). Poverty: A study of town life. London: Longmans.

Sen, A. (1997). Inequality reexamined. Oxford: Oxford University Press.

Sen, A. (2001). Development as freedom. Oxford: Oxford University Press.

Siddiqui, A. (2006). Macroeconomic returns to education in south Asia. Journal of Economic Cooperation, 27(4), 25-44

Thapa, S. B. (2010). The Educational Kuznets Curve: A case of Nepal. Tribhuvan University Journal, 27 (1-2). 
Thapa, S. B. (2011). Measurement of educational inequality in Nepal. The Economic Journal of Nepal, 34 (2).

Thirlwall, A. P. (2006). Growth and development, 8th ed. Palgrave Macmillan

Todaro, M. P. (2001). Economic development. Delhi (Indian branch): Addison Wesley Longman Pvt. Ltd.

UNDP (United Nations Development Program) (1997). Human development report 1997. Author.

UNDP (United Nations Development Program) (2012). Human development report 2012. Author.

UNDP (United Nations Development Program) (2013). Human development report 2013. Author.

UNESCO (United Nations Educational Scientific and Cultural Organization) (2013). Literacy: Poverty and development (down loaded from unesco.org on 4/8/2013). 